\title{
Psychedelic therapy as a complementary treatment approach for alcohol use disorders
}

\author{
PETER EISCHENS* and WILLIAM LEIGH ATHERTON
}

Department of Addictions \& Rehabilitation Studies, East Carolina University, Health Sciences Building, Greenville, NC, USA

(Received: December 7, 2017; accepted: March 26, 2018)

\begin{abstract}
Background: Traditional treatment interventions for alcohol use disorders (AUD) have produced mixed outcomes and the global increase in AUDs demands novel and innovative approaches to addiction treatment. Psychedelic substances have been reintroduced into the Western medical community as a potential intervention to complement the treatment of AUDs. Objectives: This paper will discuss the implications of using psychedelic substances as a complementary approach within the treatment of AUDs. Methods: A thorough review of pertinent research focused on the use of psychedelics in relation to the affective, cognitive, social, legal, and spiritual issues commonly associated with AUDs. Results: Research suggests the clinical efficacy and safety of psychedelic therapy as a complementary treatment for AUDs. Conclusion: Future directions and implications to AUD treatment are provided.
\end{abstract}

Keywords: psychedelic substances, alcohol use disorders, complementary and integrative approach

\section{INTRODUCTION}

According to the recent US National Epidemiological Survey on Alcohol and Related Conditions, the prevalence of a lifetime occurrence of an alcohol use disorder (AUD) in the United States hovers just under 30\% (Grant et al., 2015). These numbers increase significantly when a comorbid mental illness is present (Kilgus, Maxmen, \& Ward, 2016). Additionally, the risk of disease rises with dosage increases of alcohol consumption (Room, Babor, \& Rehm, 2005). Total alcohol consumption accounts for $\sim 4 \%$ of the world's total burden of disease (Ezzati et al., 2002), despite AUDs being preventable and treatable. Current treatment modalities being used for individuals with AUDs exhibit low efficacy in producing lasting positive outcomes, especially during the initial recovery period (Marlatt \& Witkiewitz, 2002). Complementary interventions for AUDs have the potential to create more robust treatments with greater successful outcomes.

Common treatment models for AUDs include screening and brief interventions, specialized treatment programs, and mutual help groups (Room et al., 2005). Brief interventions are typically utilized in primary care settings after a patient has been identified as abusing alcohol. The goal of a brief intervention may be to limit the alcohol use of the patient prior to the development of an AUD (Tam, Knight, \& Liaw, 2016). Specialized treatment may include components of withdrawal management, therapy, pharmacotherapy, and residential or outpatient rehabilitation (Room et al., 2005). Mutual help groups typically refer Alcoholics Anonymous (AA) or Narcotics Anonymous (NA) organizations. The primary stated outcome of groups, such as AA and NA, is chemical abstinence (Alcoholic Anonymous, 2001). Pharmacological therapies, such as acamprosate and naltrexone, for treating addiction have also increased throughout the past few decades.

The effectiveness of pharmacological therapies for addiction is often measured by chemical abstinence and outcomes have been moderately successful (Caputo et al., 2003; Krampe, Spies, \& Ehrenreich, 2011). These treatments attempt to illicit behavior change (Krampe et al., 2011) and decrease alcohol cravings (Caputo et al., 2003; Kalk \& Lingford-Hughes, 2014). However, most pharmacological interventions require daily medication intake to be effective and have the potential to produce negative side effects, including extreme physical illness (Krampe et al., 2011), use disorder behaviors (Stein et al., 2011), and acute toxicity (Brennan \& Van Hout, 2014).

The efficacy of the currently applied treatment methods is questionable. Approximately $25 \%$ of patients remain abstinent 1 year after treatment (Walters, Bennett, \& Miller, 2000). For those who do not seek treatment, remission rates may further decline (Moos \& Moos, 2006). Researchers have reported that patients seeking addiction treatment will have an average of 3.5 treatment attempts, indicating a lack of effectiveness in current treatment modalities for longterm recovery (Anglin, Hser, \& Grella, 1997). Early recovery in particular is associated with elevated relapse rates and

\footnotetext{
* Corresponding author: Peter Eischens, MS; Department of Addictions \& Rehabilitation Studies, East Carolina University, Health Sciences Building 4425, Mail Stop 668, Greenville, NC 27834, USA; Phone: +1 252744 6300; Fax: +1 252744 6302; E-mail: Eischensp16@students.ecu.edu
}

This is an open-access article distributed under the terms of the Creative Commons Attribution-NonCommercial 4.0 International License, which permits unrestricted use, distribution, and reproduction in any medium for non-commercial purposes, provided the original author and source are credited, a link to the CC License is provided, and changes - if any - are indicated. 
situational challenges (Marlatt \& Witkiewitz, 2002), which may require explicit and targeted interventions. Formal treatment typically occurs within the initial months of an individual's recovery; however, cognitive impairments that increase susceptibility to relapse persist for up to 1 year (Stavro, Pelletier, \& Potvin, 2013). Significant cognitive impairments during the first year of chemical abstinence (Stavro et al., 2013) and diminished inhibitory control over drinking (Field, Wiers, Christiansen, Fillmore, \& Vester, 2010) create urgency within the initial recovery period to effectively prevent full relapse. Early recovery may be the most poignant period for effective interventions. A recent study of 175 subjects undergoing outpatient treatment demonstrated a relapse rate greater than $50 \%$ within the first 4 weeks of treatment (Charney, Zikos, \& Gill, 2010).

The lack of treatment efficacy coupled with the global increase in substance use disorders demands novel approaches to addiction treatment, particularly during early recovery (Tupper, Wood, Yensen, \& Johnson, 2015). Alcohol substantially impacts domains of physical, psychological, social, and spiritual health, which should be addressed during this critical period (Heather, 1994). As the counseling community begins to experience greater acceptance of introspective practices (Johansen \& Krebs, 2015), psychedelic treatment models present as a viable option for novel addiction treatment that promotes introspection and addresses the domains of wellness most impacted by AUDs (Ross, 2012). The standardization of clinical psychedelic treatment (Johnson, Richards, \& Griffiths, 2008) and renewed interest in the use of psychedelics on a myriad of biopsychosocial issues demonstrates the potential for psychedelic therapy to be a legitimate complementary intervention for the treatment of AUDs.

\section{PSCYHEDELICS AND AUD TREATMENT DISORDER}

Using psychedelics to treat AUDs is not a new concept (Abuzzahab \& Anderson, 1971) and past research has demonstrated evidence for alcohol treatment potential (Krebs \& Johansen, 2012). Psychedelic substances currently being studied to treat AUDs are described as classic hallucinogens, including psilocybin (4-phosphoryloxy-N,N-dimethyltryptamine), lysergic acid diethylamide (LSD), and ayahuasca (Bogenschutz et al., 2015; Grinspoon \& Bakalar, 1979; Krebs \& Johansen, 2012; Talin \& Sanabira, 2017; Thomas, Lucas, Capler, Tupper, \& Martin, 2013). Numerous studies prior to the prohibition of psychedelic research demonstrated the efficacy of psychedelics in the treatment of AUDs, although results have been difficult to generalize due to a lack of standardization in treatment, dose, participant criteria, and participant follow-up (Abuzzahab \& Anderson, 1971). A modern meta-analysis reviewing six of those early studies found significant evidence for decreases in alcohol misuse after a single LSD session in randomized controlled trials (Krebs \& Johansen, 2012). Congruently, Bogenschutz et al. (2015) recently reported a significant increase in alcohol abstinence following one to two psilocybin sessions (0.3-0.4 mg). Significant improvements were also recorded for alcohol cravings, self-efficacy, and motivation
(Bogenschutz et al., 2015). The native Amazonian brew, ayahuasca, recently studied in Canada with First Nations individuals with substance use disorders, was found to decrease alcohol use and promote lasting positive changes (Thomas et al., 2013).

Researchers have explained the future potential for psychedelics to effectively treat addiction (Bogenschutz \& Johnson, 2016; Bogenschutz \& Pommy, 2012). Psychedelics produce an array of acute and long-term affects, which may address several key biopsychosocial issues associated with AUDs. These include mood and affect issues (Grob et al., 2011; Kilgus et al., 2016; National Alliance on Mental Illness, 2010), cognitive issues (Bogenshutz \& Johnson, 2016; Stavro et al., 2013), thought content and processing issues (Mann, 2003; Sher, Wood, Richardson, \& Jackson, 2005), relational issues (Charney et al., 2010; Fadiman, 2016; Moos \& Moos, 2006), legal issues (Hendricks, Clark, Johnson, Fontaine, \& Cropsey, 2014; Room et al., 2005; Stavro et al., 2013), and spirituality (Allen, Nieuwsma, Pollitt, \& Blazer, 2014; Griffiths, Richards, Johnson, McCann, \& Jesse, 2008; Walton-Moss, Ray, \& Woodruff, 2013).

\section{Mood and affective issues}

Mood disorders often co-occur with AUDs or may develop through excessive substance use (Doughty \& Hunt, 1999; Kilgus et al., 2016; Kushner, 2014; Li \& Moore, 2001; Sher et al., 2005). About $50 \%-78 \%$ of individuals with a mental health disorder have a lifetime occurrence of a co-occurring substance use disorder (Biegel, Beimers, Stevenson, Ronis, \& Boyle, 2009; Kilgus et al., 2016; National Alliance on Mental Illness, 2010). Moreover, depression and related mental illness symptomatology are exacerbated by substance use disorders (Cheng \& McBride, 2013; Doughty \& Hunt, 1999), which may hinder recovery. For example, anxiety has been found to accelerate the development of AUDs and can inhibit recovery (Butler, Karkhanis, Jones, \& Weiner, 2016). To effectively treat AUDs, comorbid mood disorders must be addressed.

Psychedelics have been found to positively affect depression, anxiety, and obsessive-compulsive disorder (Grob et al., 2011; Moreno, Wiegand, Taitano, \& Delgado, 2006). A single dose of psilocybin $(0.2 \mathrm{mg})$ has been shown to decrease anxiety in cancer patients and decrease scores on the Beck Depression Inventory at the 6-month follow-up (Grob et al., 2011). For treatment of AUDs, psychedelic experiences have the capacity to produce temporary cathartic events that are often directly related to past and current life experiences (Bogenschutz \& Johnson, 2016). Participants have reported that their psychedelic use has given them an understanding of what provides them with happiness (Zamaria, 2016), an insight which may be motivating for individuals new to recovery who cannot envision an enjoyable life without alcohol. Furthermore, unlike alcohol, psychedelic use is not associated with an increase or exacerbation of depression or anxiety (Johansen \& Krebs, 2015).

\section{Cognitive issues}

AUDs are associated with several cognitive impairments (Stavro et al., 2013). A comprehensive meta-analysis 
conducted by Stavro et al. (2013) found significant impairments of verbal fluency, speed of processing, working memory, attention, problem solving, inhibition, verbal learning, verbal memory, and visuospatial abilities in chronic alcoholics who had been chemically abstinent for a short period of time (less than 1 month). Cognitive impairments remained relatively unchanged at 1 year of chemical abstinence but improved thereafter (Stavro et al., 2013).

Psychedelics may mediate some of the cognitive impairment propagated by AUDs. Psychedelic effects primarily occur as an agonist of the serotonin $5-\mathrm{HT}_{2 \mathrm{~A}}$ receptors (Nichols, 2004). Bogenschutz and Johnson (2016) hypothesize that the downregulation of the $5-\mathrm{HT}_{2 \mathrm{~A}}$ receptors may reduce relapse related to anxiety and stress. Neuroimaging has demonstrated that psilocybin increases functional connectivity with the default mode network and the taskpositive network (Carhart-Harris et al., 2012). Psilocybin also decreases cognitive processing of negative stimuli and increases positive mood, a factor which predicts a decreased likelihood of relapse (Bogenschutz \& Johnson, 2016).

An additional cognitive mechanism of psychedelic use is the facilitation of alternate states of consciousness (ASC; Richards, 2015). Horváth, Szummer, and Szabo (2017) have argued that ASC accessed through psychedelic use signifies latent cognitive capacity, which can offer significant phenomenological insight to the user. They posit that psychedelic experiences produce visionary states that are legitimate phenomenological experiences, which can be analyzed and studied (Horváth et al., 2017). Catharsis can occur when unconscious content materializes into the conscious psyche of the user to be processed and integrated (Pahnke, Kurland, Unger, Savage, \& Grof, 1970). In terms of cognitive safety, a double-blind, placebo controlled study on psilocybin use in healthy adults found no negative implications for somatic health (Hasler, Grimberg, Benz, Huber, \& Vollenweider, 2004). The researchers also reported that the effects of ASC induced through psilocybin could be integrated psychologically by the subject (Hasler et al., 2004).

\section{Thought content and process issues}

Suicide and suicidal gestures are associated with AUDs (Mann, 2003; Sher et al., 2005). Approximately 25\% of completed suicides involved alcohol (Kilgus et al., 2016). Researchers have suggested that suicidal thoughts and gestures in patients with AUDs may be mediated through therapeutic or pharmacological treatments (Sher et al., 2005). Psychedelic use has been associated with significantly less past month psychological distress and past year suicidal ideation (Hendricks, Thorne, Clark, Coombs, \& Johnson, 2015). Specifically, in a review comparing 191,832 respondents of the National Survey on Drug Use and Health from 2008 to 2012, psilocybin use was found to be potentially protective against psychological stress and suicidality (Hendricks, Johnson, \& Griffiths, 2015). An additional study of 130,000 US adults indicated no association between psychedelic use and past year psychological distress or suicidality (Johansen \& Krebs, 2015).

Psychedelic substances have the potential to motivate introspection and critical self-examination that persists beyond the psychedelic session (Zamaria, 2016). Acute effects for psychedelic use within a session may include both bliss and joy as well as paranoia and anxiety (Bogenschutz \& Johnson, 2016). Acute anxiety is commonly reported in anticipation of psychedelic intake; however, participants have also described a marked decrease in anxiety during days following a session (Zamaria, 2016). A psychedelic experience can promote non-judgmental attitudes toward inner experiences and defusion or objective separation from difficult thoughts and emotions, such as anxiety (Soler et al., 2016). Anecdotal reports from a microdosing self-study have revealed a decrease in general anxiety and an alleviation of depression symptoms for some participants (Fadiman, 2016).

\section{Social issues}

Psychedelics have the potential to moderate some of the social upheaval experienced in early recovery and enhance interpersonal wellness. Social resources have been identified as a predictor which reduces the likelihood of relapse (Moos \& Moos, 2006). Congruently, social and interpersonal problems have been reported as predictors of relapse in early recovery (Charney et al., 2010). Psychedelic use may increase tolerance for the worldviews of others and acceptance of the self (McGlothlin \& Arnold, 1971). The mechanism of ego dissolution within the psychedelic experience facilitates feelings of unity consciousness and increased feelings of connectedness to other people (Zamaria, 2016). Subjective reports from microdosing volunteers reveal decreases in social anxiety, increased capacity to live in the present, and decreased triggering related to trauma, which may have inhibited social integration (Fadiman, 2016). The mediation of social anxiety coupled with an increased desire for personal connectedness may facilitate the cultivation of social resources imperative for individuals in early recovery.

\section{Legal issues}

AUDs are often associated with crime, traffic incidents, and other intentional and unintentional injuries (Rehm et al., 2003; Room et al., 2005). AUDs have been associated with elevated aggression and higher lifetime impulsivity (Field et al., 2010; Sher et al., 2005; Stavro et al., 2013). For example, around $50 \%$ of homicides involve alcohol (Kilgus et al., 2016). Furthermore, impulsivity has been identified as a predictor for relapse and premature attempts at sobriety (Charney et al., 2010). Room et al. (2005) have speculated that the association between alcohol and crime is due to a reduction of anxiety regarding the legal consequences of behavior, which increases risk-taking and aggression. Impaired cognition to problem-solving skills may also increase the likelihood that an individual abusing alcohol may react to conflict more emotionally (Pliner \& Cappell, 1974; Room et al., 2005; Sayette, Wilson, \& Elias, 1993).

Animal trials of psilocybin ingestion have observed a decrease in aggressive behavior (Kostowski, Rewerski, \& Piechocki, 1972) and psychedelics have been used in the past to treat criminal behavior in offenders. The most wellknown study of using psychedelics to reduce recidivism was the Concord Prison Experiment led by Tim Leary between 
1961 and 1963 (Doblin, 1998). The study was described by Leary as a success in terms of reducing recidivism and decreasing the incidence of new crimes from parolees who participated in group psychedelic psychotherapy sessions. However, Doblin (1998) uncovered the initial fallibility of Leary's reporting and the actual data revealed no significant decrease in either recidivism or the incidence of new crimes. A more recent study investigating the relationship between psychedelic use and recidivism for 25,622 substanceinvolved offenders suggested that psychedelic use within this population promoted chemical abstinence and positive behavior (Hendricks et al., 2014). These researchers speculated that this prosocial behavior may reduce the likelihood of recidivism among offenders. Further research should explore the potential for psychedelic substances to decrease behaviors related to AUDs and crime.

\section{Spirituality}

The influence of religion and spirituality on recovery has been identified as a beneficial component for long-term success in recovery from addiction (Walton-Moss et al., 2013). Spiritual change or spiritual awakenings have been found to predict 30-day chemical abstinence for individuals attending AA meetings (Zemore, 2007). In comparison to other psychiatric disorders, AUDs are most closely attached to spiritual interventions, either through AA or 12-step-based treatments (Allen et al., 2014). Traditional 12-step programs rely on a higher-power and promote spiritual growth (Morris, 2006) to reinforce the importance of spirituality within the recovery process. Regardless of the known importance of spirituality in recovery, some researchers have suggested that treatment professionals should avoid providing overtly religious or spiritual treatments to individuals with AUDs (Allen et al., 2014). Prior to any intervention, including psychedelic intervention, clinicians may assess whether the individual being treated would benefit from a spiritual or religious experience (Allen et al., 2014).

In a double-blind study using psilocybin to induce mystical-type experiences in psychedelically naive adults, more than half of the participants rated the experience as one of the five most personally and spiritually meaningful in their lives at the 14-month follow-up (Griffiths et al., 2008). These experiences also initiated positive changes in attitude, behavior, and life satisfaction. Ego dissolution has been hypothesized as the mechanism within the psychedelic experience that facilitates the mystical experience (Nour, Evans, Nutt, \& Carhart-Harris, 2016). This process of blurring the boundaries between the self and the greater whole has been a primary therapeutic benefit of psychedelic therapy (Nour et al., 2016). Mystical-type experiences frequently occur in higher dose administration (Bogenschutz \& Johnson, 2016), although even smaller doses have demonstrated the capacity to facilitate ego dissolution (Lebedev et al., 2015). Psychedelic substances have been used for religious or sacred purposes by cultures for thousands of years (Grinspoon \& Bakalar, 1979) and it was not until recently that their use has evolved from spiritual development to abuse in party-like settings (Ross, 2012). The religious and spiritual implications of psychedelic use have been identified as a primary argument for their legalization (Fadiman, 2011) and must be considered for the treatment of AUDs.

Psychedelic substances demonstrate promise as a complementary treatment for AUDs that can positively affect several issues related to both early and long-term recovery. Furthermore, the common co-occurrence of AUDs with mental illness requires a treatment that adequately addresses both conditions (Room et al., 2005). Current and past research has demonstrated the safety and efficacy of psychedelic therapy for a variety of disorders, including AUDs. Psychedelics have the potential to address common biopsychosocial issues related to AUDs. However, treatment applications, barriers to treatment implementation, and future directions must be considered to demonstrate the efficacy of psychedelic therapy as part of the treatment of AUDs.

\section{Treatment applications}

Common models of psychedelic therapy applied in past and present research include psychedelic-peak therapy, psycholytic therapy, and microdosing. The psychedelic-peak therapeutic approach involves a single high dose (300-1,500 $\mu \mathrm{g}$ of LSD; 2-3.5 $\mathrm{g}$ of psilocybin) session in conjunction with some psychotherapy preceding and following the session for integration (Pahnke et al., 1970; Sessa, 2005). The psychedelic-peak approach facilitates mystical experiences or what have been described as "religious epiphany" (Strassman, 1995 , p. 131). The psycholytic therapeutic approach involves multiple low doses of LSD $(25-150 \mu \mathrm{g})$ or psilocybin over the course of several psychotherapeutic sessions (Pahnke et al., 1970; Sessa, 2005; Strassman, 1995). Psycholytic treatment is intended to manifest cognitive material to be processed during a therapeutic session. Microdosing is the routine ingestion of sub-perceptual doses of a psychedelic substance (typically about $1 / 10$ of the recreational amount) every 3-4 days (Fadiman, 2011). Microdosing psychedelics is a relatively new concept to Western medicine and clinical investigations have yet to occur, which determine the efficacy and safety of this practice. However, subjective reports collected from a current volunteer of selfstudy have revealed an overall improvement in functioning for those engaging in this practice (Fadiman, 2016).

Current treatment models, such as brief interventions, rehabilitation, or mutual-help groups, may already have viable systems in place to allow efficient integration of the different psychedelic treatments. Congruently, psychedelic therapy should not be viewed as singular treatment but rather as a complement to established therapeutic models (Fadiman, 2011). For example, brief interventions may become more effective and meaningful with the inclusion of a single-dose psychedelic-peak therapy session to illicit a sudden dramatic behavior change. Outpatient and inpatient rehabilitation treatment programs may benefit from including multiple-dose psycholytic therapy into already established therapeutic practices to explore deeper issues of trauma and self-efficacy. Long-term participation in mutual-help groups could benefit from the incorporation of microdosing protocols to provide subtle improvements in overall functioning and well-being (Fadiman, 2016). The qualities of the various psychedelic treatment 
modalities present viable options for already recognized interventions.

A psychedelic treatment modality that has already demonstrated efficacy in clinical practice globally (Krupitsky \& Grineko, 1997) and in the United States (Kolp, Friedman, Young, \& Krupitsky, 2006) to treat AUDs is Ketamine psychedelic therapy (KPT). Originally developed and used as an anesthetic, ketamine varies from the classic hallucinogens because of its dissociative qualities and federally recognized medical benefits. However, ketamine is able to produce psychoactive effects similar to other psychedelics, depending on the dosage administered (White, Way, \& Trevor, 1982). The KPT treatment model combines psychotherapy with ketamine utilization followed by integration. Krupitsky et al. (1992) administered a combination of KPT and aversion therapy to a sample of 86 patients with AUD who had failed to achieve sobriety during a 3-month treatment period. These patients achieved almost 70\% $(n=60)$ alcohol abstinence at the 1-year follow-up compared with $24 \%$ of the 100 patients in the control group (Krupitsky et al., 1992). Similar clinical observations were reported by Kolp et al. (2006) who developed and tested five different treatment modalities until the results of Krupitsky were replicated. The most successful modality was composed of a 3-week group inpatient treatment with two ketamine sessions. Patients participated in daily encounter and psychoeducation groups in addition to daily yoga, journaling, and meditation. Of the 15 patients in this group, $\sim 70 \%$ achieved alcohol abstinence at the 1-year follow-up. Participants also reported increases in mental health and an overall improvement in well-being (Kolp et al., 2006).

\section{Barriers to implementation}

Foremost, utilizing psychedelic substances to treat AUDs remains severely limited by federal regulation (Nutt, King, \& Nichols, 2013) and stigma (Grinspoon \& Bakalar, 1979). Psychedelic substances continue to be categorized as an illicit Schedule 1 drug and are inaccurately associated with addiction. Unlike other drugs such as alcohol or nicotine, psychedelics do not produce the reinforcing neurological effects, which are associated with addiction (Kilgus et al., 2016; O'Brien, 2001). Psychedelics have not been associated with craving or withdrawal (Johnson et al., 2008) and they do not activate the reward system within the mesolimbic pathway (Nichols, 2004). Additionally, repeated psychedelic ingestion reduces $5-\mathrm{HT}_{2 \mathrm{~A}}$ receptors which accelerates chemical tolerance and reduces the likelihood of dependence (Roth, Berry, Kroeze, Willins, \& Kristiansen, 1998).

Despite decades of research which have demonstrated the safety of using psychedelic substances in clinical settings (Johnson et al., 2008), challenging experiences continue to occur for some individuals engaging in psychedelic use (Carbonaro et al., 2016; Hill, 2017). Although psychedelic experiences may be unpleasant or even terrifying, Richards (2015, p. 86) explained that "its purpose is not to torment but to teach." Including an experienced guide who can sit with an individual during a psychedelic session is recommended (Fadiman, 2011) and currently practiced in clinical research settings to minimize distress during challenging experiences (Johnson et al., 2008). Hallucinogenic persisting perception disorder has been estimated to occur in a few cases per million (Halpern \& Pope, 2003); however, most negative side effects of psychedelic use can be mediated through standardized clinical settings and screening criteria, which excludes participants who have a family history of psychosis (Johnson et al., 2008). Regardless, psychedelic substances must be recognized as powerful tools to be respected and used with proper intent (Fadiman, 2011).

Conceptualizations of recovery and abstinence-based models of treatment create additional barriers for the implementation of psychedelic treatment. The use of psychedelic substances becomes limited when associating recovery with chemical abstinence. Traditional addiction treatment models and recovery programs promote chemical abstinence as the operational definition of recovery (Kilgus et al., 2016), propagating an impression of failure for those individuals who cannot abstain, and creating a barrier for individuals who may improve with complementary treatments. Additionally, the use of psychedelics to treat AUDs may conflict with the formation of a recovery identity needed to cultivate beneficial social support from abstinence-based groups such as AA (Rodriguez \& Smith, 2014).

Secondary illicit drug use has been identified as a predictor of relapse (Charney et al., 2010), although non-abstinent recovery can be achieved for individuals who do not develop dependence on other substances (Dawson et al., 2005). Traditional models of recovery require abstinence from illicit drugs, which may exclude potentially beneficial substances, such as psychedelics. An additional group who could potentially benefit from psychedelic use are individuals who misuse alcohol, but do not meet full criteria for an AUD. A significant segment of the population that does not qualify for a use disorder or that demonstrate mild symptoms has been able to reduce their alcohol intake without formalized treatment or mutual-help groups (Dawson et al., 2005). In fact, recovery rates for individuals with AUDs would likely be higher if studies included more samples with subjects whose use has not crossed the barrier to a use disorder. The average US adult who abuses alcohol will likely follow a course of recovery that includes continued albeit reduced drinking with occasional periods of symptoms related to AUDs, which resolve after 5-10 years (Dawson et al., 2005). Psychedelics may assist in shortening the average trajectory of AUD symptoms and prevent negative social and health consequences related to alcohol misuse.

Another limitation to exploring psychedelic substances in the treatment of AUDs is the lack of experience afforded to the younger generation of mental health professionals interested in this treatment modality. Due to the federal prohibition of psychedelics, most individuals born after the mid-century psychedelic renaissance have not had the same exposure to these substances as today's leading psychedelic researchers and practitioners. For those of us who are new to the planet, we may lack the wisdom to be trepidatious regarding psychedelic substances, because we did not experience the political and cultural backlash of the 1970s (Ross, 2012). Although the potential for psychedelic substances to treat addiction appears evident, caution regarding their use and promotion is warranted through a lack of generational inexperience. 


\section{Future directions}

Moving forward, additional empirical evidence regarding the feasibility, efficacy, and effectiveness of psychedelic use in clinical settings is necessary (Tupper et al., 2015). Previous research is often anecdotal and does not meet the clinical standards of modern medicine (Sessa, 2005). Addiction treatment professionals will require staged trials building upon the evidence base before endorsing the treatment of substance use disorders with a drug, which has a history of unsupervised nonclinical abuse (Tupper et al., 2015). Various treatment modalities and clinical trials using psychedelics to treat AUD must continue and expand.

Regardless of whether psychedelics are used to treat addiction, the benefits associated with achieving ASC indicates a need to further investigate mechanisms for facilitating such experiences in the treatment of addiction (Burdick \& Adinoff, 2013). Alternative interventions, such as holotropic breathwork, have the potential to facilitate ASC without the use of psychedelic substances (Brewerton, Eyerman, Cappetta, \& Mithoefer, 2012; Grof, 2012). Additionally, mindfulness-based relapse prevention has demonstrated the potential to supplement recovery from addiction and may be appealing to individuals who do not want to be attached to a religion-based modality (Buttery, 2009).

The effects of alcohol on our society extend beyond those individuals with an AUD. General alcohol misuse in the United States accounts for substantial numbers of fatalities, such as accidents and violent crimes (Heather, 1994). Psychedelics as a brief intervention may provide an effective psychosocial intervention for anyone misusing alcohol to prevent further alcohol-related societal distress. Rapid entry into treatment once a drinking problem has been identified predicts recovery outcomes (Moos \& Moos, 2006). The facilitation of brief-interventions with psychedelics may expedite the realization of a drinking problem within an individual and encourage formalized treatment earlier in the recovery process. Future studies should explore the implications of incorporating psychedelics into brief interventions for AUD.

Nicotine addiction is another area, which should continue to be addressed through empirical clinical research. Within the United States, the prevalence rate for nicotine addiction is about $36 \%$ and along with alcohol is considered the most serious substance use problem in the country (Kilgus et al., 2016). A recent pilot study on nicotine addiction found that $80 \%$ of research participants were able to quit smoking after one to three therapeutic sessions with psilocybin in conjunction with therapy (Johnson, Garcia-Romeu, Cosimano, \& Griffiths, 2014). Future research should continue to explore the efficacy of psychedelic substances in the treatment of nicotine addiction.

\section{CONCLUSIONS}

Novel addiction treatments are required to decrease the global burden of disease related to alcohol consumption and to establish interventions which produce more favorable treatment outcomes. The legality of using psychedelic substances for the treatment of AUDs creates substantial risk for punishment and is not currently recommended. However, research exploring psychedelic substances to treat addiction and issues related to AUDs have demonstrated results that warrant further investigation into psychedelic therapy as a complementary approach to AUD treatment. Researchers and professionals in the addiction counseling field should further consider the role of psychedelics as a complementary intervention, and counselors should advocate for the legalization of psychedelic substances to be included in the treatment of addictions.

Funding sources: None.

Authors' contribution: PE is a primary writer, researcher, and editor. WLA is a writer and editor.

Conflict of interest: There are no declared conflicts of interest with the following manuscript.

Biographical note: $\mathrm{PE}$ is a doctoral student from East Carolina University. He has a MS in Counseling Psychology with an emphasis in Rehabilitation from St. Cloud State University. Dr. WLA has a MA in Mental Health Counseling and Behavioral Medicine from Boston University School of Medicine and a PhD in Rehabilitation Counseling and Administration from East Carolina University.

\section{REFERENCES}

Abuzzahab, F. S., \& Anderson, B. J. (1971). A review of LSD treatment in alcoholism. International Pharmacopsychiatry, 6(4), 223-235. doi:10.1159/000468273

Alcoholic Anonymous. (2001). Alcoholics anonymous (4th ed.). New York, NY: A.A. World Services.

Allen, J. P., Nieuwsma, J. A., Pollitt, M. J., \& Blazer, D. G. (2014). Recovery on higher ground: Spirituality in the treatment of substance abuse: Considering spirituality and religion during recovery can enhance treatment outcomes. Current Psychiatry, 13(2), 24-40. Retrieved from http://link.galegroup.com/apps/doc/ A363190288/HRCA?u=gree96177\&sid=HRCA\&xid=3f663ab0

Anglin, M. D., Hser, Y. L., \& Grella, C. E. (1997). Drug addiction and treatment careers among clients in the drug abuse and treatment outcome study. Psychology of Addictive Behaviors, 11(4), 308-323. doi:10.1037/0893-164X.11.4.308

Biegel, D. E., Beimers, D., Stevenson, L. D., Ronis, R. J., \& Boyle, P. (2009). Predictors of referral to supported employment among consumers with co-occurring mental and substance use disorders. Community Mental Health Journal, 45(6), 427-438. doi:10.1007/ s10597-009-9242-3

Bogenschutz, M. P., Forcehimes, A. A., Pommy, J. A., Wilcox, C. E., Barbosa, P. C. R., \& Strassman, R. J. (2015). Psilocybinassisted treatment for alcohol dependence: A proof-of-concept study. Journal of Psychopharmacology, 29(3), 289-299. doi:10.1177/0269881114565144

Bogenschutz, M. P., \& Johnson, M. W. (2016). Classic hallucinogens in the treatment of addictions. Progress in 
Neuro-Psychopharmacology and Biological Psychiatry, 64, 250-258. doi:10.1016/j.pnpbp.2015.03.002

Bogenschutz, M. P., \& Pommy, J. M. (2012). Therapeutic mechanisms of classic hallucinogens in the treatment of addictions: From indirect evidence to testable hypotheses. Drug Testing and Analysis, 4(7-8), 543-555. doi:10.1002/dta.1376

Brennan, R., \& Van Hout, M. C. (2014). Gamma-hydroxybutyrate (GHB): A scoping review of pharmacology, toxicology, motives for use, and user groups. Journal of Psychoactive Drugs, 46(3), 243-251. doi:10.1080/02791072.2014.921746

Brewerton, T. D., Eyerman, J. E., Cappetta, P., \& Mithoefer, M. C. (2012). Long-term abstinence following holotropic breathwork as adjunctive treatment of substance use disorders and related psychiatric comorbidity. International Journal of Mental Health and Addiction, 10(3), 453-459. doi:10.1007/s11469-011-9352-3

Burdick, B. V., \& Adinoff, B. (2013). A proposal to evaluate mechanistic efficacy of hallucinogens in addiction treatment. The American Journal of Drug and Alcohol Abuse, 39(5), 291-297. doi:10.3109/00952990.2013.811513

Butler, T. R., Karkhanis, A. N., Jones, S. R., \& Weiner, J. L. (2016). Adolescent social isolation as a model of heightened vulnerability to comorbid alcoholism and anxiety disorders. Alcoholism: Clinical and Experimental Research, 40(6), 1202-1214. doi:10.1111/acer.13075

Buttery, H. (2009). Mindfulness meditation paves the road to recovery in addiction. CrossCurrents, 12(4), 4-5. Retrieved from http://search.proquest.com.jproxy.lib.ecu.edu/docview/ 763269794? accountid $=10639$

Caputo, F., Addolorato, G., Lorenzini, F., Domenicali, M., Greco, G., del RE, A., Gasbarrini, G., Stefanini, G. F., \& Bernardi, M. (2003). Gamma-hydroxybutyric acid versus naltrexone in maintaining alcohol abstinence: An open randomized comparative study. Drug and Alcohol Dependence, 70(1), 85-91. doi:10.1016/ S0376-8716(02)00340-X

Carbonaro, T. M., Bradstreet, M. P., Barrett, F. S., MacLean, K. A., Jesse, R., Johnson, M. W., \& Griffiths, R. R. (2016). Survey study of challenging experiences after ingesting psilocybin mushrooms: Acute and enduring positive and negative consequences. Journal of Psychopharmacology, 30(12), 1268-1278. doi:10.1177/0269881116662634

Carhart-Harris, R. L., Leech, R., Erritzoe, D., Williams, T. M., Stone, J. M., Evans, J., Sharp, D. J., Feilding, A., Wise, R. G., \& Nutt, D. J. (2012). Functional connectivity measures after psilocybin inform a novel hypothesis of early psychosis. Schizophrenia Bulletin, 39(6), 1343-1351. doi:10.1093/schbul/sbs117

Charney, D. A., Zikos, E., \& Gill, K. J. (2010). Early recovery from alcohol dependence: Factors that promote or impede abstinence. Journal of Substance Abuse Treatment, 38(1), 42-50. doi:10.1016/j.jsat.2009.06.002

Cheng, H. G., \& McBride, O. (2013). A prospective evaluation of disability associated with alcohol use disorders in the United States: An application of the quantile regression approach. American Journal on Addictions, 22(6), 551-557. doi:10.1111/j.1521-0391.2013.12035.x

Dawson, D. A., Grant, B. F., Stinson, F. S., Chou, P. S., Huang, B., \& Ruan, W. (2005). Recovery from DSM-IV alcohol dependence: United States, 2001-2002. Addiction, 100(3), 281-292. doi:10.1111/j.1360-0443.2004.00964.x

Doblin, R. (1998). Dr. Leary's Concord Prison experiment: A 34-year follow-up study. Journal of Psychoactive Drugs, 30(4), 419-426. doi:10.1080/02791072.1998.10399715
Doughty, J. D., \& Hunt, B. (1999). Counseling clients with dual disorders: Information for rehabilitation counselors. Journal of Applied Rehabilitation Counseling, 30(3), 3-10. Retrieved from http://search.proquest.com.jproxy.lib.ecu.edu/docview/ 216447066? accountid=10639/

Ezzati, M., Lopez, A. D., Rodgers, A., Vander Hoorn, S., Murray, C. J., \& Comparative Risk Assessment Collaborating Group. (2002). Selected major risk factors and global and regional burden of disease. The Lancet, 360(9343), 1347-1360. doi:10.1016/S0140-6736(02)11403-6

Fadiman, J. (2011). The psychedelic explorer's guide: Safe, therapeutic, and sacred journeys. Rochester, VT: Inner Traditions/ Bear \& Co.

Fadiman, J. (2016). Microdose research: Without approvals, control groups, double-blinds, staff or funding. Psychedelic Press, 15, 53-59. Retrieved from https://www.researchgate.net/ publication/308138461_Microdose_research_without_approvals_ control_groups_double_blinds_staff_or_funding

Field, M., Wiers, R. W., Christiansen, P., Fillmore, M. T., \& Verster, J. C. (2010). Acute alcohol effects on inhibitory control and implicit cognition: Implications for loss of control over drinking. Alcoholism: Clinical and Experimental Research, 34(8), 1346-1352. doi:10.1111/j.1530-0277.2010.01218.x

Grant, B. F., Goldstein, R. B., Saha, T. D., Chou, S. P., Jung, J., Zhang, H., Pickering, R. P., Ruan, W. J., Smith, S. M., Huang, B., \& Hasin, D. S. (2015). Epidemiology of DSM-5 alcohol use disorder: Results from the National Epidemiologic Survey on Alcohol and Related Conditions III. JAMA Psychiatry, 72(8), 757-766. doi:10.1001/jamapsychiatry.2015.0584

Griffiths, R. R., Richards, W. A., Johnson, M. W., McCann, U. D., \& Jesse, R. (2008). Mystical type experiences occasioned by psilocybin mediate the attribution of personal meaning and spiritual significance 14 months later. Journal of Psychopharmacology, 22(6), 621-632. doi:10.1177/0269881108094300

Grinspoon, L., \& Bakalar, J. B. (1979). Psychedelic drugs reconsidered. New York, NY: Basic Books.

Grob, C. S., Danforth, A. L., Chopra, G. S., Hagerty, M., McKay, C. R., Halberstadt, A. L., \& Greer, G. R. (2011). Pilot study of psilocybin treatment for anxiety in patients with advancedstage cancer. Archives of General Psychiatry, 68(1), 71-78. doi:10.1001/archgenpsychiatry.2010.116

Grof, S. (2012). Healing our deepest wounds: The holotropic paradigm shift. Newcastle, WA: Stream of Experience Productions.

Halpern, J. H., \& Pope, H. G. (2003). Hallucinogen persisting perception disorder: What do we know after 50 years? Drug and Alcohol Dependence, 69(2), 109-119. doi:10.1016/S03768716(02)00306-X

Hasler, F., Grimberg, U., Benz, M. A., Huber, T., \& Vollenweider, F. X. (2004). Acute psychological and physiological effects of psilocybin in healthy humans: A double-blind, placebocontrolled dose-effect study. Psychopharmacology, 172(2), 145-156. doi:10.1007/s00213-003-1640-6

Heather, N. (1994). Alcohol, accidents, and aggression. BMJ: British Medical Journal, 308(6939), 1254-1254. doi:10.1136/ bmj.308.6939.1254

Hendricks, P. S., Clark, C. B., Johnson, M. W., Fontaine, K. R., \& Cropsey, K. L. (2014). Hallucinogen use predicts reduced recidivism among substance-involved offenders under community corrections supervision. Journal of Psychopharmacology, 28(1), 62-66. doi:10.1177/0269881113513851 
Hendricks, P. S., Johnson, M. W., \& Griffiths, R. R. (2015). Psilocybin, psychological distress, and suicidality. Journal of Psychopharmacology, 29(9), 1041-1043. doi:10.1177/026988 1115598338

Hendricks, P. S., Thorne, C. B., Clark, C. B., Coombs, D. W., \& Johnson, M. W. (2015). Classic psychedelic use is associated with reduced psychological distress and suicidality in the United States adult population. Journal of Psychopharmacology, 29(3), 280-288. doi:10.1177/0269881114565653

Hill, S. J. (2017). Confrontation with the unconscious: Jungian depth psychology and psychedelic experience. Herndon, VA: Muswell Hill Press.

Horváth, L., Szummer, C., \& Szabo, A. (2017). Weak phantasy and visionary phantasy: The phenomenological significance of altered states of consciousness. Phenomenology and the Cognitive Sciences, 17(1), 117-129. doi:10.1007/s11097-0169497-4

Johansen, P. Ø., \& Krebs, T. S. (2015). Psychedelics not linked to mental health problems or suicidal behavior: A population study. Journal of Psychopharmacology, 29(3), 270-279. doi:10.1177/0269881114568039

Johnson, M. W., Garcia-Romeu, A., Cosimano, M. P., \& Griffiths, R. R. (2014). Pilot study of the 5-HT2AR agonist psilocybin in the treatment of tobacco addiction. Journal of Psychopharmacology, 28(11), 983-992. doi:10.1177/026988 1114548296

Johnson, M. W., Richards, W. A., \& Griffiths, R. R. (2008). Human hallucinogen research: Guidelines for safety. Journal of Psychopharmacology, 22(6), 603-620. doi:10.1177/026988 1108093587

Kalk, N. J., \& Lingford-Hughes, A. R. (2014). The clinical pharmacology of acamprosate. British Journal of Clinical Pharmacology, 77(2), 315-323. doi:10.1111/bcp.12070

Kilgus, M. D., Maxmen, J. S., \& Ward, N. G. (2016). Essential psychopathology \& its treatment. New York, NY: W. W. Norton \& Company.

Kolp, E., Friedman, H. L., Young, M. S., \& Krupitsky, E. (2006). Ketamine enhanced psychotherapy: Preliminary clinical observations on its effectiveness in treating alcoholism. The Humanistic Psychologist, 34(4), 399-422. doi:10.1207/s15473 333thp3404_7

Kostowski, W., Rewerski, W., \& Piechocki, T. (1972). The effects of some hallucinogens on aggressiveness of mice and rats. Pharmacology, 7(4), 259-263. doi:10.1159/000 136297

Krampe, H., Spies, C. D., \& Ehrenreich, H. (2011). Supervised disulfiram in the treatment of alcohol use disorder: A commentary. Alcoholism: Clinical and Experimental Research, 35(10), 1732-1736. doi:10.1111/j.1530-0277.2011.01519.x

Krebs, T. S., \& Johansen, P. Ø. (2012). Lysergic acid diethylamide (LSD) for alcoholism: Meta -analysis of randomized controlled trials. Journal of Psychopharmacology, 26(7), 994-1002. doi:10.1177/0269881112439253

Krupitsky, E. M., \& Grinenko, A. Y. (1997). Ketamine psychedelic therapy (KPT): A review of the results of ten years of research. Journal of Psychoactive Drugs, 29(2), 165-183. doi:10.1080/ 02791072.1997.10400185

Krupitsky, E. M., Grineko, A. Y., Berkaliev, T. N., Paley, A. I., Tetrov, U. N., Mushkov, K. A., \& Borodikin, Y. S. (1992). The combination of psychedelic and aversive approaches in alcoholism treatment: The affective contra-attribution method.
Alcoholism Treatment Quarterly, 9(1), 99-105. doi:10.1300/ J020V09N01_09

Kushner, M. G. (2014). Seventy-five years of comorbidity research. Journal of Studies on Alcohol and Drugs. Supplement, 75(Suppl. 17), 50-58. doi:10.15288/jsads.2014.s17.50

Lebedev, A. V., Lövdén, M., Rosenthal, G., Feilding, A., Nutt, D. J., \& Carhart-Harris, R. L. (2015). Finding the self by losing the self: Neural correlates of ego-dissolution under psilocybin. Human Brain Mapping, 36(8), 3137-3153. doi:10.1002/ hbm. 22833

Li, L., \& Moore, D. (2001). Disability and illicit drug use: An application of labeling theory. Deviant Behavior: An Interdisciplinary Journal, 22(1), 1-21. doi:10.1080/01639620 1750065784

Mann, J. J. (2003). Neurobiology of suicidal behavior. Nature Reviews Neuroscience, 4(10), 819-828. doi:10.1038/nrn1220

Marlatt, G. A., \& Witkiewitz, K. (2002). Harm reduction approaches to alcohol use: Health promotion, prevention, and treatment. Addictive Behaviors, 27(6), 867-886. doi:10.1016/ S0306-4603(02)00294-0

McGlothlin, W. H., \& Arnold, D. O. (1971). LSD revisited: A ten-year follow-up of medical LSD use. Archives of General Psychiatry, 24(1), 35-49. doi:10.1001/archpsyc.1971. 01750070037005

Moos, R. H., \& Moos, B. S. (2006). Rates and predictors of relapse after natural and treated remission from alcohol use disorders. Addiction, 101(2), 212-222. doi:10.1111/j.1360-0443.2006. 01310.x

Moreno, F. A., Wiegand, C. B., Taitano, E. K., \& Delgado, P. L. (2006). Safety, tolerability, and efficacy of psilocybin in 9 patients with obsessive-compulsive disorder. Journal of Clinical Psychiatry, 67(11), 1735-1740. doi:10.4088/JCP.v67n1110

Morris, K. (2006). Hallucinogen research inspires "neurotheology". The Lancet, 5(9), 732. doi:10.1016/S1474-4422(06) 70541-5

National Alliance on Mental Illness. (2010). Mental illness and diagnosis. Retrieved from http://www2.nami.org/Content/ NavigationMenu/Inform_Yourself/About_Mental_Illnes_ By_Illness/Dual_Diagnosis_Substance_Abuse_and_Mental_ Illness.htm

Nichols, D. E. (2004). Hallucinogens. Pharmacological Therapy, 101(2), 131-181. doi:10.1016/j.pharmthera.2003.11.002

Nour, M. M., Evans, L., Nutt, D., \& Carhart-Harris, R. L. (2016). Ego-dissolution and psychedelics: Validation of the EgoDissolution Inventory (EDI). Frontiers in Human Neuroscience, 10, 269. doi:10.3389/fnhum.2016.00269

Nutt, D. J., King, L. A., \& Nichols, D. E. (2013). Effects of schedule I drug laws on neuroscience research and treatment innovation. Nature Reviews Neuroscience, 14(8), 577-585. doi: $10.1038 / \mathrm{nrn} 3530$

O'Brien, C. P. (2001). Drug addiction and drug abuse. In J. G. Hardman, L. E. Limbird, P. B. Molinoff, R. W. Ruddon, \& A. G. Gilman (Eds.), Goodman and Gilman's the pharmacological basis of therapeutics (pp. 574-639). New York, NY: McGraw-Hill.

Pahnke, W. N., Kurland, A. A., Unger, S., Savage, C., \& Grof, S. (1970). The experimental use of psychedelic (LSD) psychotherapy. Journal of the American Medical Association, 212(11), 1856-1863. doi:10.1001/jama.1970.03170240060010

Pliner, P., \& Cappell, H. (1974). Modification of affective consequences of alcohol: A comparison of social and solitary 
drinking. Journal of Abnormal Psychology, 83(4), 418-425. doi: $10.1037 / \mathrm{h} 0036884$

Rehm, J., Room, R., Graham, K., Monteiro, M., Gmel, G., \& Sempos, C. T. (2003). The relationship of average volume of alcohol consumption and patterns of drinking to burden of disease: An overview. Addiction, 98(9), 1209-1228. doi:10.1046/j.1360-0443.2003.00467.x

Richards, T. W. (2015). Sacred knowledge: Psychedelics and religious experiences. New York, NY: Columbia University Press.

Rodriguez, L., \& Smith, J. A. (2014). 'Finding your own place': An interpretative phenomenological analysis of young men's experience of early recovery from addiction. International Journal of Mental Health and Addiction, 12(4), 477-490. doi:10.1007/s11469-014-9479-0

Room, R., Babor, T., \& Rehm, J. (2005). Alcohol and public health. The Lancet, 365(9458), 519-530. doi:10.1016/S01406736(05)70276-2

Ross, S. (2012). Serotonergic hallucinogens and emerging targets for addiction pharmacotherapies. Psychiatric Clinics of North America, 35(2), 357-374. doi:10.1016/j.psc.2012.04.002

Roth, B. L., Berry, S. A., Kroeze, W. K., Willins, D. L., \& Kristiansen, K. (1998). Serotonin 5 HT 2A receptors: Molecular biology and mechanisms of regulation. Critical Reviews ${ }^{\mathrm{TM}}$ in Neurobiology, 12(4), 319-338. doi:10.1615/CritRevNeurobiol. v12.i4.30

Sayette, M. A., Wilson, T., \& Elias, M. J. (1993). Alcohol and aggression: A social information processing analysis. Journal of Studies on Alcohol and Drugs, 54(4), 399-407. doi:10.15288/ jsa.1993.54.399

Sessa, B. (2005). Can psychedelics have a role in psychiatry once again? British Journal of Psychiatry, 186(6), 457-458. doi:10.1192/bjp.186.6.457

Sher, K. J., Wood, M. D., Richardson, A. E., \& Jackson, K. M. (2005). Subjective effects of alcohol 1: Effects of the drink and drinking context. In M. Earleywine (Ed.), Mind altering drugs: The science of subjective experience (pp. 86-134). Oxford, UK: Oxford University Press.

Soler, J., Elices, M., Franquesa, A., Barker, S., Friedlander, P., Feilding, A., Pascual, J. C., \& Riba, J. (2016). Exploring the therapeutic potential of ayahuasca: Acute intake increases mindfulness-related capacities. Psychopharmacology, 233(5), 823-829. doi:10.1007/s00213-015-4162-0

Stavro, K., Pelletier, J., \& Potvin, S. (2013). Widespread and sustained cognitive deficits in alcoholism: A meta-analysis. Addiction Biology, 18(2), 203-213. doi:10.1111/j.1369-1600. 2011.00418.x
Stein, L. A. R., Lebeau, R., Clair, M., Martin, R., Bryant, M., Storti, S., \& Monti, P. (2011). A web-based study of gamma hydroxybutyrate (GHB): Patterns, experiences, and functions of use. The American Journal on Addictions, 20(1), 30-39. doi:10.1111/j.1521-0391.2010.00099.x

Strassman, R. J. (1995). Hallucinogenic drugs in psychiatric research and treatment perspectives and prospects. The Journal of Nervous and Mental Disease, 183(3), 127-138. doi:10.1097/ 00005053-199503000-00002

Talin, P., \& Sanabria, E. (2017). Ayahuasca's entwined efficacy: An ethnographic study of ritual healing from 'addiction.' International Journal of Drug Policy, 44, 23-30. doi:10.1016/ j.drugpo.2017.02.017

Tam, C., Knight, A., \& Liaw, S. T. (2016). Alcohol screening and brief interventions in primary care-evidence and a pragmatic practice-based approach. Australian Family Physician, 45(10), 767-770. Retrieved from http://search.proquest.com.jproxy. lib.ecu.edu/docview/1829017464? accountid=10639

Thomas, G., Lucas, P., Capler, N. R., Tupper, K. W., \& Martin, G. (2013). Ayahuasca-assisted therapy for addiction: Results from a preliminary observational study in Canada. Current Drug Abuse Reviews, 6(1), 30-42. doi:10.2174/15733998113099 990003

Tupper, K. W., Wood, E., Yensen, R., \& Johnson, M. W. (2015). Psychedelic medicine: An emerging therapeutic paradigm. Canadian Medical Association Journal, 187(14), 1054-1059. doi:10.1503/cmaj.141124

Walters, S. T., Bennett, M. E., \& Miller, J. H. (2000). Reducing alcohol use in college students: A controlled trial of two brief interventions. Journal of Drug Education, 30(3), 361-372. doi:10.2190/JHML-0JPD-YE7L-14CT

Walton-Moss, B., Ray, E. M., \& Woodruff, K. (2013). Relationship of spirituality or religion to recovery from substance abuse: A systematic review. Journal of Addictions Nursing, 24(4), 217-226. doi:10.1097/JAN.0000000000000001

White, P. F., Way, W. L., \& Trevor, A. J. (1982). Ketamine - Its pharmacology and therapeutic uses. Anesthesiology, 56(2), 119-136. doi:10.1097/00000542-198202000-00007

Zamaria, J. A. (2016). A phenomenological examination of psilocybin and its positive and persisting aftereffects. NeuroQuantology, 14(2), 285-296. doi:10.14704/nq.2016.14.2.943

Zemore, S. (2007). A role for spiritual change in the benefits of 12-step involvement. Alcoholism: Clinical and Experimental Research, 31(S3), 763-793. doi:10.1111/j.1530-0277.2007. 00499.x 